\title{
Variation of Total Soluble Protein Content in Fruit among Six Greenhouse Tomato Cultivars
}

\author{
Ryo Matsuda ${ }^{1,2}$ and Chieri Kubota \\ Controlled Environment Agriculture Center (CEAC), School of Plant \\ Sciences, College of Agriculture and Life Sciences, University of Arizona, \\ Tucson, AZ 85721-0036
}

Additional index words. fruit ripening, molecular farming, plant-made pharmaceuticals (PMP), subunit vaccine, Solanum lycopersicum

\begin{abstract}
Tomato has been considered as a potential biological production platform for plant-made pharmaceuticals (PMPs). However, information is limited for protein productivity and dynamics in tomato fruit. As part of our PMP production project, total soluble protein (TSP) content of green and red fruits was analyzed for selected six greenhouse cultivars. The six cultivars consisted of various fruit types (including cluster, cherry, mini plum, and grape types) with sizes ranging from 10 to 150 and from 14 to 188 $\mathrm{g}$ fresh weight for green and red fruits, respectively. In fruit TSP content per unit dry weight (DW), approximately seven- to eightfold variation was observed among cultivars for both green and red fruits. There was no significant correlation between fruit TSP content per DW and fruit DW or fruit type over the cultivars irrespective of fruit ripening stage, indicating that fruit weight or fruit type of a cultivar cannot be an indicator of the TSP content per DW. There was also an inconsistent trend in differences in fruit TSP content per whole fruit between green and red fruit among cultivars. Our results suggest that a low-yielding cultivar can produce high TSP content per unit ground area resulting from high TSP content per DW in fruit. A background tomato cultivar or genotype candidate for commercial PMP production should thus be selected from among various fruit types considering both yield potential and fruit TSP content.
\end{abstract}

Plant-made pharmaceutical (PMP) protein production is attracting considerable interest as a novel system for production of biopharmaceuticals. Using plant-based expression systems such as stable transformation and transient expression with plant virus vectors, various PMPs can be synthesized, including antigens, hormones, growth factors, blood proteins, cytokines, enzymes, and antibodies. Compared with conventional fermentation-based systems using recombinant microbes or transformed animal cells, transgenic plant systems have advantages, including lower cost, higher scalability, fewer downstream purification processes, and lower contamination risk of potential human pathogens or toxins (Daniell et al., 2001; Mason and Arntzen, 1995; Mason et al., 2002; Thanavala et al., 2006; Twyman et al., 2003). Greenhouse tomato (Solanum lycopersicum) production is considered as a suitable production system for PMPs because of the relatively efficient transformation system available for

Received for publication 19 May 2010. Accepted for publication 23 Aug. 2010.

We thank Patricia Rorabaugh and Myles Lewis (University of Arizona) for providing us fruit samples.

${ }^{1}$ Current address: Department of Biological and Environmental Engineering, Graduate School of Agricultural and Life Sciences, The University of Tokyo, Bunkyo-ku, Tokyo, Japan.

${ }^{2}$ To whom reprint requests should be addressed; e-mailamatsuda@mail.ecc.u-tokyo.ac.jp. tomato (Mason et al., 2002), high biomass yield in the greenhouse (Twyman et al., 2003), possible structural containment to prevent transgene flow to the outside (Twyman et al., 2003), and capacity of environmental control for steering the plant growth to maximize the protein productivity (Matsuda et al., 2009). To date, various PMP proteins have been successfully expressed using transgenic tomatoes (Alvarez et al., 2006, 2008; Huang et al., 2005; Jani et al., 2002; Lou et al., 2007; Ramírez et al., 2007; Sandhu et al., 2000; Sun et al., 2007; Zhang et al., 2006). However, selection of baseline (wild-type) tomato cultivars used for PMP seems to be not systematic; rather, it was based on seed availability or practicality (e.g., open-pollinated versus hybrid).

A high expression of transgenic protein is desirable in PMP production. For edible vaccine production in tomato, for example, high vaccine protein content could increase the efficiency of mucosal immunization per unit of mass of the freeze-dried powder for oral administration, increasing a chance of the contact of vaccine protein to the mucous membrane per dose of powder within the safe range of vaccine concentration. A high target protein content per unit of mass would also be favorable for other PMP proteins that have to be purified before being used because protein purification efficiency is in general largely influenced by the initial protein content in raw materials.

Alvarez et al. (2006) reported that green tomato fruit had significantly greater target protein (F1-V antigen protein for plague) expression than red fruit, suggesting a rapid decrease in protein during the fruit ripening process. Our recent study using F1-V transgenic tomato plants revealed that fruit total soluble protein (TSP) and F1-V protein contents per unit dry weight (DW) markedly decreased in fruit increasing its size (Matsuda et al., 2010). The highest TSP and F1-V contents were observed for the smallest fruit harvested in its early green stage (Matsuda et al., 2010). We also found that there was a positive correlation between $\mathrm{F} 1-\mathrm{V}$ protein content and TSP content per unit DW in green fruits of various sizes, suggesting that the overall TSP content is an important factor determining transgene protein content. In fact, the expression level of transgene is often presented on a TSP basis in scientific literature relevant to PMP (Haq et al., 1995; Mason et al., 1992, 1996; Zhang et al., 2006), which may imply that most biotechnologists tacitly assume a linear relationship between the transgene product and TSP. However, because protein is not a traditional quality trait in tomato, almost no attention has been paid to fruit TSP content in tomato. Although protein content in beefsteak and cherry tomatoes was briefly reported by Jones (2008) and recent proteomic analysis revealed protein dynamics during fruit development (Carrari et al., 2006; Faurobert et al., 2007), there is no detailed information on the degree to which fruit TSP content varies among tomato cultivars with a wide range of fruit types. We previously reported that 'Durinta', a commercially cultured, cluster-type cultivar, produced significantly larger fruit containing significantly lower TSP content per unit DW in fruit than the transgenic tomato expressing F1-V and its background 'TA234' (Matsuda et al., 2009). This suggests a considerable difference in TSP content depending on cultivars and fruit type. Based on our finding on the relationship between fruit size and TSP content per unit DW in tomato (Matsuda et al., 2009, 2010), we hypothesized that there might be a negative correlation between them

Here, to better understand the variation of fruit TSP content among cultivars and the relationship between fruit size and TSP content in tomato, we quantified TSP content in green and red fruits of six greenhouse tomato cultivars, including various fruit types.

\section{Materials and Methods}

Plant material. Six greenhouse tomato cultivars, all F1 hybrids, were used as plant material. They were selected based on their fruit types: 'Cupido' (grape), 'E.2233541' (mini plum), 'DR1178' (cherry cluster), 'Campari' (medium cluster), 'Baylee' (medium cluster), and 'Brilliant' (large cluster) (Table 1).

Growth conditions. All plants were grown hydroponically with a high-wire system in a temperature-controlled greenhouse located in Tucson, AZ. Seeds were sown on 8 July 2007 and 108 seedlings per cultivar were transplanted onto rockwool slabs on $23 \mathrm{Aug}$. 2007. The modified Hoagland's nutrient 
solution described in Wu and Kubota (2008) was automatically supplied using a drip irrigation system. Average daytime and nighttime air temperatures, determined during the growth of fruit subject to the analyses (for $\approx 2$ months), were $23 \pm 3{ }^{\circ} \mathrm{C}$ and $16 \pm 2{ }^{\circ} \mathrm{C}$, respectively. Daily average relative humidity was maintained above $45 \%$. Under the conditions of the present study, all genotypes exhibited indeterminate growth.

Fruit harvest. Fruit samples were harvested on 13 May 2008. Four plants per cultivar (24 plants in total) were randomly selected and one plant was considered as an experimental unit. Trusses at the similar developmental stages were selected from the plants, and one green and one red fruit were harvested from each plant at once. Fruits at the green stage and at the red stage were selected according to the color classification for fresh tomatoes (U.S. Department of Agriculture, 1991) and were used for subsequent analyses. Because green-fruit TSP content per unit DW is sensitive to fruit growing stage (Matsuda et al., 2010), green fruits were selected so that their average fresh weight (FW) was $60 \%$ to $80 \%$ of the average $\mathrm{FW}$ of the corresponding red fruits. After FW was measured, the fruit was longitudinally divided in half through the stem scar for determination of DW and TSP content. Fruit DW was determined after being oven-dried at $80{ }^{\circ} \mathrm{C}$ for at least $5 \mathrm{~d}$. The other half was kept at $-80{ }^{\circ} \mathrm{C}$ until TSP analysis.

Biochemical assay. Fruit TSP content was determined by Lowry-Folin assay (Lowry et al., 1951) as described in Matsuda et al. (2009). Calibration curves were made with bovine serum albumin.

Data analysis. One plant was considered as a replication and there were four replications per each cultivar. The experiment was conducted once. Significant difference tests ( $t$ test, analysis of variance, and least significant difference) were performed using statistical software (JMP Version 8.0.1; SAS Institute Inc., Cary, NC).

\section{Results and Discussion}

Green-fruit FW of the six cultivars varied from 10 to $150 \mathrm{~g}$ (Fig. 1A). Red-fruit FW varied from 14 to $188 \mathrm{~g}$. There was also variation of DW for green and red fruits among cultivars (Fig. 2B). Regardless of cultivar, redfruit DW was not significantly greater than green-fruit DW (Table 1). This means that the increase in red-fruit FW compared with greenfruit FW was almost the result of an increase in water content. To eliminate this "dilution" effect by water content, TSP content per unit of mass was evaluated on a DW basis rather a FW basis in subsequent analyses.

There was significant seven- to eightfold variation in fruit TSP content per unit DW among cultivars in both green and red fruits (Fig. 1C). Among cultivars surveyed here, TSP content per unit DW was high in 'DR1178' and low in 'Cupido' for both green and red fruits (Table 1). In 'Brilliant', TSP content per unit DW was the lowest for green fruit but the
Table 1. Summary of significant difference tests for Figure 1 among cultivars and between green and red fruits in each genotype.

\begin{tabular}{|c|c|c|c|c|c|c|c|c|c|}
\hline \multirow[b]{2}{*}{ Cultivar } & \multirow[b]{2}{*}{ Fruit type } & \multicolumn{2}{|c|}{ Fresh $w^{z}{ }^{z}$} & \multicolumn{2}{|c|}{ Dry $w^{2}$} & \multicolumn{2}{|c|}{ TSPy $^{y}$ content per dry $w^{z}$} & \multicolumn{2}{|c|}{ TSP content per fruit } \\
\hline & & Green & $\overline{\text { Red }}$ & Green & $\operatorname{Red}$ & Green & Red & Green & Red \\
\hline Cupido & Grape & $\mathrm{d}$ & $\mathrm{d}^{*}$ & $\mathrm{~d}$ & c & $\mathrm{d}$ & $\mathrm{e}$ & $\mathrm{b}$ & $\mathrm{d}$ \\
\hline E. 2233541 & Mini plum & d & $\mathrm{cd}^{*}$ & $\mathrm{~cd}$ & $\mathrm{c}$ & bc & $\mathrm{cd}$ & $\mathrm{b}$ & $\mathrm{cd}$ \\
\hline DR1178 & Cherry cluster & $\mathrm{c}$ & $\mathrm{c}^{*}$ & $\mathrm{c}$ & $\mathrm{c}$ & a & $a b$ & a & $\mathrm{c}$ \\
\hline Campari & Medium cluster & $\mathrm{b}$ & $\mathrm{b}$ & $\mathrm{b}$ & $\mathrm{b}$ & $\mathrm{cd}$ & $d^{*}$ & $\mathrm{~b}$ & $\mathrm{bc}^{*}$ \\
\hline Baylee & Medium cluster & $\mathrm{b}$ & $b^{*}$ & $\mathrm{~b}^{*}$ & $\mathrm{~b}$ & $\mathrm{~b}$ & $\mathrm{bc}$ & $\mathrm{a}$ & $\mathrm{b}$ \\
\hline Brilliant & Large cluster & a & $a^{*}$ & $\mathrm{a}$ & $\mathrm{a}$ & d & $a^{*}$ & $\mathrm{~b}$ & $a^{*}$ \\
\hline
\end{tabular}

${ }^{2}$ Different letters in each column represent significant difference by least significant difference after analysis of variance $(P<0.05)$. An asterisk $\left(^{*}\right)$ represents significant difference by $t$ test $(P<0.05)$ between green and red fruits in each cultivar and measurement item.

${ }^{\mathrm{y}}$ Total soluble protein.
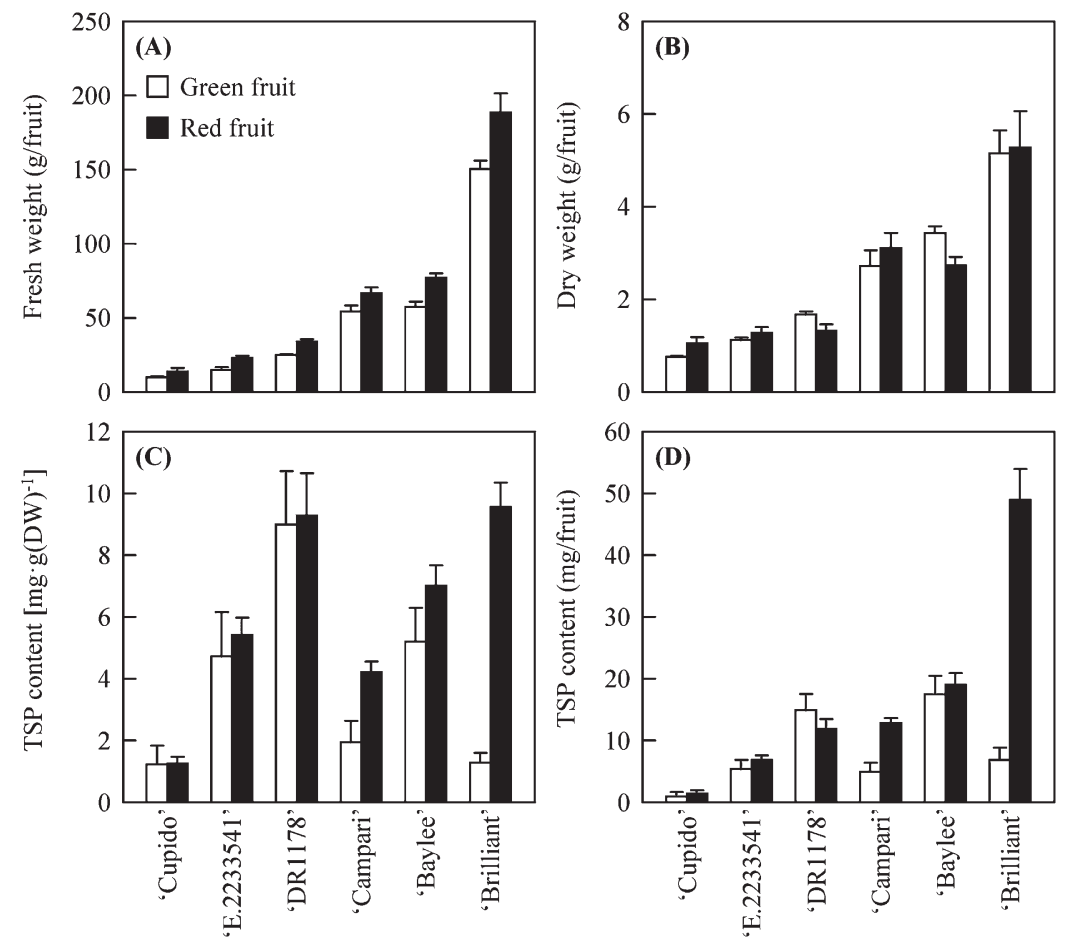

Fig. 1. Fresh weight (A), dry weight (DW) (B), total soluble protein (TSP) content per unit DW (C), and TSP content per whole fruit (D) in green (open column) and red (closed column) fruits of the six tomato cultivars. Vertical bars represent SEM $(n=4)$. See Table 1 for significant differences among cultivars and between green and red fruits in each genotype.

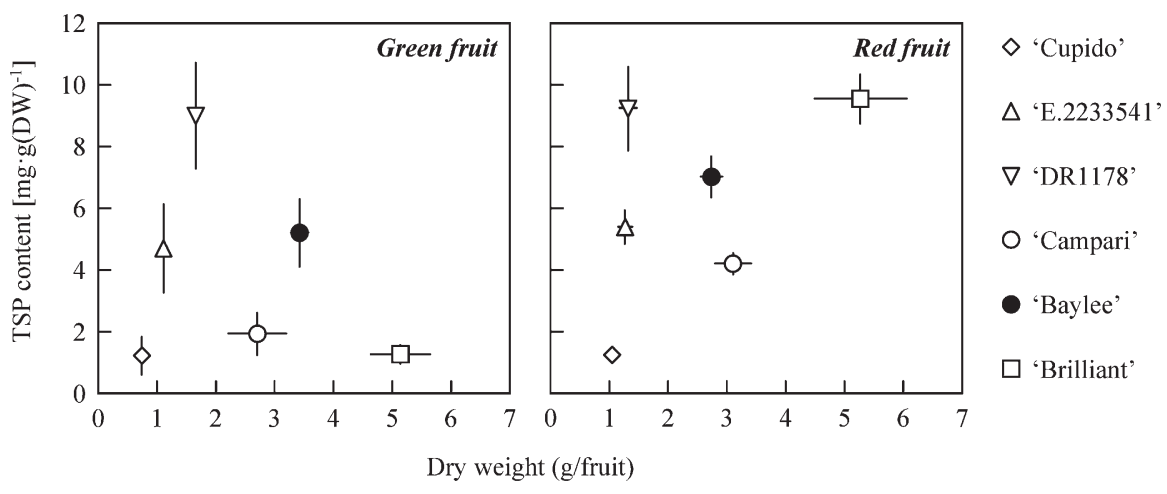

Fig. 2. The relationship between total soluble protein (TSP) content per unit dry weight (DW) and fruit DW in green (left panel) or red (right panel) fruit of the six tomato cultivars: Cupido (diamond), E.2233541 (triangle), DR1178 (inverted triangle), Campari (open circle), Baylee (filled circle), and Brilliant (square). Vertical and horizontal bars represent SEM $(n=4)$. 
highest for red fruit in all cultivars (Table 1). Fruit TSP content per unit DW in red fruit in 'Campari' and 'Brilliant' was significantly higher than that in green fruit, whereas the other cultivars exhibited similar TSP content per unit DW in green and red fruits (Table 1). This may imply that protein dynamics during the fruit-maturing process are cultivar-specific. We previously reported that fruit TSP content per unit DW in the F1-V transgenic tomato markedly decreased, whereas green fruit increased its size in growth and development (Matsuda et al., 2010). In the same study, we also found that fruit TSP content per unit DW turned to an increase from the breakers stage to the red stage, whereas F1-V content per unit DW remained low (data not shown). Similar trends were also reported in a round ('Moneymaker'; Carrari et al., 2006) and a cherry ('Cervil'; Faurobert et al., 2007) tomato. This might be a reason why the TSP content per unit DW of red fruit was similar to or higher than that of green fruit. There was also large variation (22- to 64-fold) of TSP content per whole fruit among cultivars (Fig. 1D). The TSP content per fruit was highest in 'DR1178' and 'Baylee' for green fruit (Table 1). For red fruit, 'Brilliant' contained exceptionally high TSP content per fruit, more than twice as much as the other cultivars (Table 1).

The relationships between fruit TSP content per unit DW and fruit DW in all cultivars for green and red fruits are shown in Figure 2. In either ripening stage, no significant correlation was observed $(P>0.1)$. Thus, fruit weight or type of a tomato cultivar cannot be an indicator of its fruit TSP content per unit DW. We previously found that fruit F1-V protein content per unit DW in the $\mathrm{F} 1-\mathrm{V}$ transgenic plants was considerably higher in young, small green fruit than in mature green fruit (Matsuda et al., 2010). This higher F1-V content per unit DW in small green fruit was associated with a higher TSP content per unit DW (Matsuda et al., 2010). However, our present results indicate that a cultivar that bears small fruit does not necessarily have a high fruit TSP content per unit DW. Therefore, TSP content per unit DW may be attributed to developmental stage of fruit rather than fruit size as a phenotype.

In general, grape and cherry tomatoes are less productive than other fruit types such as cluster and beefsteak. For example, 'Cupido' grape tomato and 'DR1178' cherry cluster tomato yielded $\approx 70 \%$ to $80 \%$ as much as 'Campari' and 'Baylee' medium cluster tomatoes per unit area (P.A. Rorabaugh, personal communication). On the other hand, greenfruit TSP content per unit DW in 'DR1178' cherry cluster tomato was $\approx 1.7$ times as much as that in 'Baylee' medium cluster tomato (Fig. 1C). Thus, total TSP productivity per unit area can be 1.2 to 1.3 times higher in 'DR 1178 ' than in 'Baylee'. A background tomato cultivar or genotype used for commercial PMP production should be selected based not only on its yield potential, but also its protein content in fruit.

Our present study was conducted to quantify the variation of TSP among different cultivars and fruit ripeness stage. Therefore, it is not our intention to conclude the only one suitable cultivar for PMP production out of the cultivars subjected here. In fact, all cultivars used in this experiment were F1 hybrids, whereas cultivars subject to transformation are usually open-pollinated lines. Furthermore, we should be aware that there are several factors affecting TSP and transgene protein productivity. Alvarez et al. (2006) and Matsuda et al. (2010) found that the F1-V content per unit DW decreased with fruit growth and ripeness, and the highest productivity was expected to be obtained by harvesting young, green fruits (Matsuda et al., 2010). In contrast, Sun et al. (2007) reported that miraclin, a taste-modifying high-value protein, accumulated to almost the same level throughout fruit development in tomato. This means that the fruit growth stage to be harvested must be different depending on the target PMP protein. In addition, a suitable cultivar should depend on not only PMP protein content, but also many other factors; it must be related, for instance, to which fruit type is favorable for the end use (e.g., processed or unprocessed) and to which cultivar is suitable for the regional climate in which the plants are aimed to be grown.

Fischer and his colleagues expressed functional scFvT84.66, an antibody against the human carcinoembryonic antigen, in different plant species, including tobacco (Stoger et al., 2002), rice (Stöger et al., 2000; Torres et al., 1999), wheat (Stöger et al., 2000), pea (Perrin et al., 2000), and tomato (Stoger et al., 2002). Using these data, the expression levels of scFvT84.66 in harvest parts were compared in different species (Stoger et al., 2002). There was no correlation between the antibody content and total protein content in the harvests. They concluded that the total protein content of a given organ or tissue may not be a major determinant for choosing a species as an expression system. Their conclusion is reasonable, because the composition and localization of proteins in an organ must be considerably different depending on plant species. However, there could be a correlation between the content of a target transgene product and TSP content across cultivar within the same species, considering that a relatively similar composition and localization of proteins in a tissue or organ can be expected in the same species. Comparative analysis of transgene expression levels in various cultivars within the same species, including tomato, needs to be carried out in future research.

In summary, fruit TSP content per unit DW varied significantly among tomato cultivars and was not related to fruit type or mass of the cultivars. This indicates that fruit type cannot be used as an index for selecting a cultivar that has high TSP content. There was also an inconsistent trend in difference in TSP between green and red fruit. Our result suggests that a low-yielding cultivar can produce high TSP content per unit ground area as a result of high TSP content per unit DW in fruit. A background tomato cultivar or genotype candidate for commercial PMP production should therefore be carefully selected based on a wide survey of yield potential, fruit TSP content, and other factors from among tomatoes with various fruit types.

\section{Literature Cited}

Alvarez, M.L., H.L. Pinyerd, J.D. Crisantes, M.M. Rigano, J. Pinkhasov, A.M. Walmsley, H.S. Mason, and G.A. Cardineau. 2006. Plant-made subunit vaccine against pneumonic and bubonic plague is orally immunogenic in mice. Vaccine 24:2477-2490

Alvarez, M.L., H.L. Pinyerd, E. Topal, and G.A. Cardineau. 2008. P19-dependent and P19independent reversion of F1-V gene silencing in tomato. Plant Mol. Biol. 68:61-79.

Carrari, F., C. Baxter, B. Usadel, E. UrbanczykWochniak, M.-I. Zanor, A. Nunes-Nesi, V. Nikiforova, D. Centero, A. Ratzka, M. Pauly, L.J. Sweetlove, and A.R. Fernie. 2006. Integrated analysis of metabolite and transcript levels reveals the metabolic shifts that underlie tomato fruit development and highlight regulatory aspects of metabolic network behavior. Plant Physiol. 142:1380-1396.

Daniell, H., S.J. Streatfield, and K. Wycoff. 2001. Medical molecular farming: Production of antibodies, biopharmaceuticals and edible vaccines in plants. Trends Plant Sci. 6:219-226.

Faurobert, M., C. Mihr, N. Bertin, T. Pawlowski, L. Negroni, N. Sommerer, and M. Causse. 2007. Major proteome variations associated with cherry tomato pericarp development and ripening. Plant Physiol. 143:1327-1346.

Haq, T.A., H.S. Mason, J.D. Clements, and C.J. Arntzen. 1995. Oral immunization with a recombinant bacterial antigen produced in transgenic plants. Science 268:714-716.

Huang, Z., G. Elkin, B.J. Maloney, N. Beuhner, C.J. Arntzen, Y. Thanavala, and H.S. Mason. 2005. Virus-like particle expression and assembly in plants: Hepatitis B and Norwalk viruses. Vaccine 23:1851-1858

Jani, D., L.S. Meena, Q.M. Rizwan-ul-Haq, Y. Singh, A.K. Sharma, and A.K. Tyagi. 2002. Expression of cholera toxin B subunit in transgenic tomato plants. Transgenic Res. 11:447-454.

Jones, J.B., Jr. 2008. Tomato plant culture: In the field, greenhouse, and home garden. 2nd Ed. CRC Press, Boca Raton, FL.

Lou, X.M., Q.H. Yao, Z. Zhang, R.H. Peng, A.S. Xiong, and H.K. Wang. 2007. Expression of the human B virus large surface antigen gene in transgenic tomato plants. Clin. Vaccine Immunol. 14:464-469.

Lowry, O.H., N.J. Rosebrough, A.L. Farr, and R.J. Randall. 1951. Protein measurement with the Folin phenol reagent. J. Biol. Chem. 193:265-275.

Mason, H.S. and C.J. Arntzen. 1995. Transgenic plants as vaccine production systems. Trends Biotechnol. 13:388-392.

Mason, H.S., J.M. Ball, J.-J. Shi, X. Jiang, M.K. Estes, and C.J. Arntzen. 1996. Expression of Norwalk virus capsid protein in transgenic tobacco and potato and its oral immunization in mice. Proc. Natl. Acad. Sci. USA 93:53355340

Mason, H.S., D.M.-K. Lam, and C.J. Arntzen. 1992. Expression of hepatitis B surface antigen in transgenic plants. Proc. Natl. Acad. Sci. USA 89:11745-11749.

Mason, H.S., H. Warzecha, T. Mor, and C.J. Arntzen. 2002. Edible plant vaccines: Applications for prophylactic and therapeutic molecular medicine. Trends Mol. Med. 8:324-329.

Matsuda, R., C. Kubota, M.L. Alvarez, and G.A. Cardineau. 2009. Biopharmaceutical protein 
production under controlled environments: Growth, development, and vaccine productivity of transgenic tomato plants grown hydroponically in a greenhouse. HortScience 44:1594 1599.

Matsuda, R., C. Kubota, M.L. Alvarez, and G.A. Cardineau. 2010. Determining the optimal timing of fruit harvest in transgenic tomato expressing F1-V, a candidate subunit vaccine against plague. HortScience 45:347-351.

Perrin, Y., C. Vaquero, I. Gerrard, M. Sack, J. Drossard, E. Stöger, P. Christou, and R. Fischer. 2000. Transgenic pea seeds as bioreactors for the production of a single-chain Fv. fragment ( $\mathrm{scFV}$ ) antibody used in cancer diagnosis and therapy. Mol. Breed. 6:345-352.

Ramírez, Y.J.R., E. Tasciotti, A. Gutierrez-Ortega, A.J.D. Torres, M.T.O. Flores, M. Giacca, and M.Á.G. Lim. 2007. Fruit-specific expression of the human immunodeficiency virus type 1 Tat gene in tomato plants and its immunogenic potential in mice. Clin. Vaccine Immunol. 14: 685-692.

Sandhu, J.S., S.F. Krasnyanski, L.L. Domier, S.S. Korban, M.D. Osadjan, and D.E. Buetow. 2000.
Oral immunization of mice with transgenic tomato fruit expressing respiratory syncytia virus-F protein induces a systemic immune response. Transgenic Res. 9:127-135.

Stoger, E., M. Sack, Y. Perrin, C. Vaquero, E. Torres, R.M. Twyman, P. Christou, and R. Fischer. 2002. Practical considerations for pharmaceutical antibody production in different crop systems. Mol. Breed. 9:149-158.

Stöger, E., C. Vaquero, E. Torres, M. Sack, L. Nicholson, J. Drossard, S. Williams, D. Keen, Y. Perrin, P. Christou, and R. Fischer. 2000. Cereal crops as viable production and storage systems for pharmaceutical $\mathrm{scFv}$ antibodies. Plant Mol. Biol. 42:583-590.

Sun, H.J., H. Kataoka, M. Yano, and H. Ezura. 2007 Genetically stable expression of functional miraculin, a new type of alternative sweetener, in transgenic tomato plants. Plant Biotechnol. J. 5:768-777.

Thanavala, Y., Z. Huang, and H.S. Mason. 2006 Plant-derived vaccines: A look back at the highlights and a view to the challenges on the road ahead. Expert Rev. Vaccines 5:249 260 .
Torres, E., C. Vaquero, L. Nicholson, M. Sack, E. Stöger, J. Drossard, P. Christou, R. Fischer, and Y. Perrin. 1999. Rice cell culture as an alternative production system for functional diagnostic and therapeutic antibodies. Transgenic Res. 8:441-449.

Twyman, R.M., E. Stoger, S. Schilliberg, P. Christou, and R. Fischer. 2003. Molecular farming in plants: Host systems and expression technology. Trends Biotechnol. 21:570-578.

U.S. Department of Agriculture. 1991. United States standards for grades of fresh tomatoes. USDA Agricultural Market Service, Washington, DC. 26 Nov. 2007. <http://www.ams.usda.gov/AMSv1.0 getfile?dDocName=STELPRDC5050331>.

$\mathrm{Wu}$, M. and C. Kubota. 2008. Effects of high electrical conductivity of nutrient solution and its application timing on lycopene, chlorophyll and sugar concentrations of hydroponic tomatoes during ripening. Sci. Hort. 116:122-129.

Zhang, X., N.A. Buehner, A.M. Hutson, M.K Estes, and H.S. Mason. 2006. Tomato is a highly effective vehicle for expression and oral immunization with Norwalk virus capsid protein. Plant Biotechnol. J. 4:419-432. 